\title{
Görsel Seçim Kampanyası ve Instagram Stratejileri: 2020 ABD Başkanlık Seçiminden Bulgular
}

\author{
Visual Political Campaigning and Instagram Strategies: Evidence from the 2020 US Presidential \\ Elections
}

Gizem Melek, Dr. Öğr. Üyesi, Yaşar Üniversitesi İletişim Fakültesi, E-posta: gizem.melek@yasar.edu.tr

https://doi.org/10.47998/ikad.889206

\author{
Anahtar Kelimeler: \\ Instagram, \\ İmge, \\ Görsel Seçim \\ Kampanyas1, \\ 2020 ABD Başkanlık \\ Seçimi, \\ İçerik Analizi.
}

Keywords:

Instagram,

Image,

Visual political

campaign,

2020 US Presidential

Elections,

Content Analysis.
$\ddot{O} z$

Bu çalışmanın amacı 2020 ABD başkanlık seçimi sırasında adayların Instagramı nasıl bir stratejiyle kullanarak seçim kampanyası aracına dönüştürdüklerini irdelemektir. $\mathrm{Bu}$ doğrultuda adayların kampanya sürecinin son bir ayını kapsayan paylaşımları odağa alınmıştır. Donald Trump'tan 92, Joe Biden'dan ise 190 olmak üzere toplam 282 görsele Russmann ve Svensson (2016)'ın Instagram'a özel tasarladıkları kodlama cetveli kullanılarak nicel içerik analizi yapılmıştır. Analizde adayların Instagram stratejileri Russmann ve Svensson (2016)'ın kodlama cetvelindeki takip eden kategorilere göre ortaya çıkarılmıştır: (1) kampanya mesajlarını yayınlamak, (2) destekçileri harekete geçirmek (mobilizasyon), (3) adayın imajını yönetmek ve (4) diğer kampanya materyallerini güçlendirmek ve tamamlamak (melez kampanya). Tanımlayıcı analiz sonuçlarına göre adaylar Instagram'ı en çok mobilizasyon amacıyla kullanırken, yayın yapma stratejisi her iki aday için de takip eden ikinci en yüksek kategori olmuştur. Adaylar imaj yönetimi açısından sadece profesyonel ortamlarda görüntülenmeyi ve hiçbir zaman özel/aile ortamında resmedilmemeyi tercih etmişlerdir. Bununla birlikte imaj yönetiminin ünlüler alt kategorisi her iki adayda da düşük oranda olmakla birlikte tespit edilmiştir. Melez kullanımı ise ne Biden ne de Trump tercih etmiştir.

\section{Abstract}

The purpose of this study is to examine how political candidates use Instagram as a strategic tool during the 2020 US Presidential elections. The article focuses on 282 Instagram posts; 92 from Donald Trump and 190 from Joe Biden during the last month of the election campaign. Drawing on Russmann and Svensson (2016), the study adopts a quantitative content analysis method to determine whether Instagram was used under the following categories: (1) broadcasting campaign messages, (2) mobilizing supporters, (3) managing the candidate's image, and (4) strengthening and complementing other campaign materials (hybrid campaign). The results show that the candidates mostly used Instagram for mobilization, while the broadcasting strategy was the second-highest category for both candidates. In terms of image management, the candidates preferred to portray themselves only in professional settings and never in a private / family setting. The celebrities subcategory of the image management was only found occasionally for both candidates. Neither Biden nor Trump preferred the use of the hybrid strategy. 


\section{Giriş}

Medyanın dijitalleşmesi ve sosyal medyanın yükselişi, siyasal iletişim dinamiklerini değiştirmektedir. Obama'nın 2008 ABD başkanlık seçimi kampanyası, sosyal medyanın etkin bir şekilde araçsallaştırılmasıyla siyasi kampanyalarda bir dönüm noktası olmuştur. O zamandan beri, hem çevrimiçi hem de sosyal medya kampanyaları siyaset dünyasında ve bilim çevrelerinde büyük ilgi görmeye başlamıştır. Seçim kampanyaları döneminde sosyal medya üzerine yapılan öncül çalışmalar, esas olarak metinsel verilere odaklanmıştır. Bununla birlikte günümüzde bu odak metinlerden Instagram, YouTube ve Snapchat gibi görsel sosyal medya platformlarına kaymaktadır (Muñoz ve Towner, 2017). Görseller ve imaj yönetimi kamuoyunun tutumunu etkileyebilen unsurlar olduğu için araştırmacılar siyasi kampanyalarda da merkezi bir konuma sahip olan görsellerin rolünü daha çok önemsemeye başlamışlardır. Görsellerle ilgili araştırmalar geleneksel televizyondan görsel sosyal medyaya kadar çeşitli platformlara odaklanmaktadır (Grabe ve Bucy, 2009; Steffan, 2020; Veneti vd., 2019). Bununla birlikte, özellikle Instagram'ın siyasi kampanyalardaki rolü son yıllarda popülarite kazanmıştır. Alan yazında bu çalışmaların görsel çerçeveleme (Muñoz ve Towner, 2017; Uluçay ve Melek, basım aşamasında), stratejik faaliyetler (Filimonov vd., 2016), imaj yönetimi (Lalancette ve Raynauld, 2019) ve/veya dijital hikâye anlatıcılığı (Liebhart ve Bernhardt, 2017; Melek ve Müyesseroğlu, 2021) gibi çeşitli yaklaşımlar üzerinden Instagram'a odaklandığı görülmektedir.

$\mathrm{Bu}$ çalışmada ise 2020 ABD başkanlık seçimleri konu edilmektedir. Bu seçim ABD tarihinde sıradışı bir süreç olarak korona virüs salgını, ırkçılık ve polis şiddeti karşıtı gösterilerin gölgesinde gerçekleşmiştir. Ayrıca seçimi kaybeden Cumhuriyetçi Parti lideri Donald Trump sonuca itiraz ederek ülke tarihinde ilk kez yönetimin hukuk kuralları ve demokrasi çerçevesinde barışçı olarak devredilmesi meselesini tartışmaya açmıştır. Seçimin son bir aylık sürecindeki yoğunlaşmış kampanya döneminde Joe Biden ve Donald Trump'ın şahsi Instagram hesaplarında paylaştıkları görsellere içerik analizi uygulanarak adayların Instagram üzerinden yürüttükleri stratejik seçim kampanyaları irdelenmiştir. Böylelikle görsel sosyal medyanın politikacılar tarafından seçim dönemlerinde nasıl araçsallaştırıldığı ortaya konularak siyasal iletişim yazınına katkı sağlanması amaçlanmaktadır.

\section{Sosyal Medya ve Seçim Kampanyaları}

Siyasal iletişimde sosyal medyanın yoğun kullanımı ile liderler, kitle iletişim araçları gibi aracılar olmadan bilgi yayabilir ve kamuoyuyla etkileşime girebilir hale gelmiştir. Siyasal iletişimde geleneksel medyanın yerini sosyal medyanın aldığına dair bir kanıt bulunmasa da geleneksel medya içeriği sosyal medyada canlı bir şekilde belgelenmekte ve tartışılmaktadır (Enli, 2017). Sosyal medya, siyasetle ilgili haber almada önemli bir kaynak haline gelmiştir. Buna bağlı olarak, bu eğilimin siyasi bilgiyi nasıl etkilediğini anlamak için artan bir ilgi bulunmaktadır (Andı vd., 2020) Dolayısıyla sosyal medya platformlarının siyasi kampanyalarda kullanımı ve olası etkileri farklı bağlamlarda incelenmektedir. Çeşitli ülkelerden bilim insanları sosyal medya platformlarının siyasi bilgi ve seçim kampanyalarına olan etkilerini de aktif olarak araştırmaktadır 
(And1 vd., 2020; Bossetta, 2018; Filimonov vd., 2016; Liebhart ve Bernhardt, 2017; Melek ve Müyesseroğlu, 2021; Pineda vd., 2020; Steffan, 2020; Turnbull-Dugarte, 2019). Son dönemlerde yapılan araştırmalar, siyasi partilerin sosyal medyayı stratejik kullanımlarına, siyasi liderlerin öz-çerçeveleme (self-framing) ve kendilerini görsel olarak sunma taktiklerine odaklanmıştır (ör. Muñoz ve Towner, 2017; Uluçay ve Melek, basım aşamasında). Diğer araştırmalar sosyal medyanın kamuoyu, siyasi katılım ve izleyici katılımı üzerindeki etkisini araştırmışlardır (ör. Towner, 2013; Eldin, 2016; Metz vd., 2020). Bu çalışmalar, seçim kampanyaları sırasında sosyal medya platformlarının kullanımının kamuoyunda daha yüksek düzeyde dikkat ve ilgi uyandırdığını göstermiştir. Liderlerin bu platformlarda daha duygusal ve özel içerik paylaştıklarında insanlar üzerinde olumlu izlenimler yarattıkları da ortaya konmuştur.

Sosyal medya platformları, liderlere diğer siyasetçiler ve seçmenlerle etkileşimde bulunmaları için doğrudan ve anında fırsatlar sağlamaktadır; ancak araştırmalar liderlerin bu çevrimiçi platformları izleyicilerle etkileşimi artırmak için kullanmadıklarını göstermektedir. Bunun yerine, sosyal medyadan yukarıdan aşağıya bir iletişim ortamı olarak yararlanmaktadırlar (Graham vd., 2013). Bu çalışmalar siyasetçilerin sosyal medyada etkileşimden ziyade geleneksel medyadaki gibi daha tek yönlü bir yayın eğiliminde olduğunu göstermektedir.

Öncül araştırmalar genellikle Twitter ve Facebook gibi metin tabanlı sosyal medya kampanyalarına (Bode ve Dalrymple, 2016; Borah, 2016; Enli ve Skogerbø, 2013; Gerodimos ve Justinussen, 2015; Goldbeck vd., 2010; Melek, 2017; Svensson ve Larsson, 2016; Towner, 2013) veya Instagram hashtagleri gibi görüntü odaklı platformların metin tabanlı içeriğgine odaklanmıştır (Highfield ve Leaver, 2015). Çünkü siyasi kampanyalar çoğunlukla metinsel sosyal medya içeriğine dayanmaktadır (Muñoz ve Towner, 2017). Ancak Instagram, YouTube, Tumblr, Pinterest ve Snapchat gibi görsel sosyal medya platformlarının artan popülaritesi ve tüketici tarafından hızla benimsenmesi, imaj yönetimi, siyasi kampanya ve öz sunum için yeni firsatlar sağlamaktadır (Muñoz ve Towner, 2017; Uluçay ve Melek, basım aşamasında). Dolayısıyla, bilim insanları fotoğraf ve video merkezli sosyal medya platformlarına olan yönelimin siyasi kampanyaları nasıl etkileyebileceğini anlamaya çalışmaktadırlar. Bazı çalışmalar Facebook, Instagram, Twitter ve Snapchat gibi metin tabanlı ve görsel merkezli platformları karşılaştırırken (ör. Bossetta, 2018; Steffan, 2020), tek bir platforma odaklanmanın "o platformun kullanımı, içeriği ve etkilerini daha iyi anlamaya olanak tanıdığı" gerekçesiyle son derece değerli ve önemli olduğu konusunda bir fikir birliği de oluşmuştur (Bode ve Vraga, 2018: 1; Liebhart ve Bernhardt, 2017; Melek ve Müyesseroğlu, 2021). Öncül çalışmalar, ilk olarak siyasi adayların Facebook zaman tüneli fotoğraflarını inceleyerek seçim kampanyalarında görsellerin rolüne değinmiştir (Cmeciu, 2014; Goodnow, 2013). Görsellere olan bu ilgi, son zamanlarda yeni bir siyasi araştırma platformu olan Instagram'a yönlendirilmiştir. Örneğin, Filimonov vd. (2016), İsveç’teki bir seçim kampanyası sırasında siyasi partilerin Instagram'1 stratejik bir iletişim aracı olarak kullandığ dört farklı yolu tanımlamıştır: (1) Seçim mesajlarını yayınlamak, (2) destekçileri harekete geçirmek, (3) partinin imajını yönetmek, (4) diğer kampanya bileşenlerini geliştirmek veya tamamlamak (karma veya melez). Turnbull-Dugarte (2019), benzer bir yaklaşımı İspanyol siyasi partilerinin 
Instagram hesaplarına uygulayarak Instagram kullanım amaçlarını tespit etmeye çalışmıştır. Liebhart ve Bernhardt (2017) ise Avusturya cumhurbaşkanlığı seçiminin galibi Alexander Van der Bellen'in Instagram üzerinden bir yıl süren seçim kampanyasındaki dijital hikâye anlatımına odaklanmıştır. Bu makale imaj türlerini belirleyerek öz temsil stratejilerini ve bir politikacının arzu edilen portreyi yansıtıp yönetmek için dijital bir platformdan nasıl yararlandığını ortaya koymuştur. Liebhart ve Bernhardt (2017) imaj türlerinin belirginliğinin önemine vurgu yapmış ve altta yatan görsel stratejilerin yeniden yapılandırılmasına olan etkilerinden bahsetmiştir. Bunlar: (1) adayın biyografisini vurgulama (biyografik strateji), (2) kampanya ekibinin sunumu (takım stratejisi) ve (3) adayın meşru bir yönetici olarak sunulması (iktidar stratejisi) şeklinde sıralanmıştır (Liebhart ve Bernhardt, 2017). Benzer bir çalışma Türkiye'de de yapılmış olup siyasetçilerin dijital hikâye anlatımı ortaya çıkarılmıştır (Melek ve Müyesseroğlu, 2021). Bu çalışma 2019 İstanbul yerel seçimleri sürecinde belediye başkanı seçilen muhalefet adayı Ekrem İmamoğlu'nun Instagram kampanyasındaki fotoğraflarının motif ve temasını nicel ve nitel yöntemleri bir arada kullanarak incelemişstir.

Görsel çerçeveleme analizi de son yıllarda yapılan Instagram çalışmalarında öne çıkmaktadır. Muñoz ve Towner (2017)'ın 2016 ABD başkanlık seçimleri sürecinde adayların öz çerçeveleme stratejilerine odaklandıkları çalışmasında görüntülerin siyasi karakter gelişimini çerçevelemede oynadığı rolü araştırmak ve hangi görüntülerin daha yüksek düzeyde etkileşim aldığını belirlemek için adayların Instagram hesaplarına içerik analizi yapılmıştır. Türkiye'de benzer yöntemi kullanan araştırmacılar Grabe ve Bucy (2009)'nin görsel çerçeveleme yaklaşımını temel alarak 2019 İstanbul yerel seçimi adaylarının öz çerçeveleme stratejilerini incelemişlerdir (Uluçay ve Melek, basım aşamasında). Çalışma sonucunda adayların daha çok "ideal aday" (the Ideal Candidate) çerçevesini kullandıkları tespit edilmiş̧tir. Bu sonuçlar Muñoz ve Towner (2017)'ın çalışmasının sonuçlarıyla da örtüşmüştür. Instagram özelinde yapılan diğer bir araştırma ise Kanada'da imaj yönetiminin etkilerini ve sonuçlarını araştırmak için ünlü siyasetine odaklanmıştır (Lalancette ve Raynauld, 2019). Bu çalışmada araştırmacılar nicel ve nitel yöntemleri hibrit bir şekilde kullanarak, Kanada Başbakanı Justin Trudeau ve partisinin, kalıcı ve giderek kişiselleştirilmiş kampanya bağlamında seçmenlere belirli bir imajı nasıl ilettiğini incelemişlerdir. Bu araştırma Trudeau'nun yönetim tarzının görsel olarak nasıl çerçevelendiğini, kişisel yaşamının Kanada Liberal Partisi'nin değerlerini ve fikirlerini desteklemek için Instagram'da nasıl kullanıldığını ve çevre, gençlik ve teknoloji gibi politika konularını tartışmak için ünlü kültür kodlarının nasıl seferber edildiğini ortaya çıkarmıştır.

\section{Siyasette Görsel İletişim ve İmaj Yönetimi}

Öncül çalışmalar, görsel iletişimin hedef kitlenin duygularını ve tutumlarını tetikleme gücüne sahip olduğu için sözlü iletişimden daha etkili olabileceğini ortaya koymuştur. Sözlü iletişimde, mesajı gönderenin alıcıyı ikna etmek için retorik becerilere ihtiyacı vardır. Ancak görsel iletişimde alıcı, hitabet becerilerine bağlı olmadan görsel mesajı yakalayabilmektedir (Blair, 2012). Ayrıca, özellikle başlangıçta görüntülerin daha 
fazla ilgi topladığı (Bucher ve Schumacher, 2006) ve metinden daha akılda kalıcı ve daha kolay yorumlanabildiği (Graber, 1996) bulunmuştur.

Görsel sembollerin ve iletişimin önemi, televizyonun en güçlü siyasi bilgi kaynağ1 haline gelmesinden bu yana siyasal iletişim alanında önemli bir konu olmuştur. Bir siyasi liderin tarzının, fiziksel görünümünün ve imajının etkisi, televizyon çağının mutlak gerçeğini oluşturmaktadır. Konuyla ilgili yetersiz sayıda çalışmaya rağmen, erken araştırmalar, siyasi aday sunumunun seçmenlerin tercihlerini değiştirdiğini kanıtlamıştır (Rosenberg vd., 1986). Bu nedenle, imaj yapımcıları, medya danışmanları ve medya profesyonelleri, liderlerin fiziksel görünüşünü, vücut dilini, 1şıklandırmasını, ortamını ve görsel çerçevedeki diğer unsurları yönetmeye başlamıştır. Politikacılar bu görsel iletişim stratejilerini günlük hayatta kullanmaya başlamışlardır. Kiminle ve nerede fotoğraflanacağı, hangi renk giyileceği ve hangi jestlerin uygulanacağı siyasi imaj inşasında taktik meseleler haline gelmiştir (Schill, 2012). Seçim kampanyalarının birçoğu profesyonel ekipler ile yönetilmekte olup bu taktikler ince detaylarına kadar planlanmaktadır.

Ana akım medya okuyucularının ve takipçilerinin sayısının azaldığı göz önüne alındığında, sosyal medyanın kullanımı siyasal iletişimin temel bir unsuru haline gelmektedir. Siyasiaktörler boşluğu sosyalmedya aracılığıyla doldurmaya çalışmaktadırlar. Statista (2021) verilerine göre aylık bir milyardan fazla aktif kullanıcısıyla en popüler görsel sosyal medya platformu olan Instagram, imaj geliştirmek ve hedeflere doğrudan hitap etmek için harika bir firsat haline gelmektedir (Turnbull-Dugarte, 2019). Ayrica Muñoz ve Towner (2017)'ın ortaya koyduğu gibi Instagram, Facebook ve Twitter'a kıyasla önemli ölçüde daha yüksek kullanıcı etkileşim oranlarına ulaşmaktadır. Buradan yola çıkarak aşağıdaki araştırma soruları kapsamında 2020 ABD Başkanlık seçimi sırasında adayların Instagram'ı nasıl bir stratejik kullanımla seçim kampanyası aracına dönüştürdükleri irdelenecektir.

AS1: Adayların Instagram kullanımı yayın (broadcasting) stratejisini içermekte midir?

AS2: Adayların Instagram kullanımı seçmenleri harekete geçirme/mobilize etme stratejisini içermekte midir?

AS3: Adayların Instagram kullanımı imaj yönetimi stratejisini kapsamakta mıdır?

AS4: Adaylar Instagram üzerinden melez kampanya stratejileri kullanmış mıdır?

AS5: Joe Biden ve Donald Trump'ın kampanya mesajlarını yayınlama, destekçileri mobilize etme, kendi imajlarını yönetme ve diğer kampanya materyallerini güçlendirip tamamlama stratejileri karşılaştırmalı olarak hangi oranlarda kullanmıştır?

\section{Yöntem}

Korona virüs salgını, 1rkçılık ve polis şiddeti karşıtı gösterilerin gölgesinde gerçekleşen ve Amerikan tarihinin sıradışı seçimlerinden biri olan bu seçim 3 Kasım 2020'de yapılmıştır. Seçimi önemli kılan bir diğer nokta da seçimi kaybeden Cumhuriyetçi 
Parti lideri Donald Trump'ın sonuca itiraz ederek ülke tarihinde ilk kez yönetimin hukuk kuralları ve demokrasi çerçevesinde barışçı olarak devredilmesi meselesini tartışmaya açması olmuştur. Donald Trump ve Joe Biden'ın stratejik Instagram kullanımını incelemek için, seçim kampanyasının en yoğun dönemi olan son bir aya odaklanılmıştır. Son ayda hem adaylar daha çok paylaşım yapmaktadır hem de seçimin son periodu olduğu için spesifik stratejiler daha net ortaya konulabilmektedir (ör. Filimonov vd., 2016). Bu doğrultuda 3 Ekim 2020 ve 3 Kasım 2020 arasındaki paylaşımlar incelenmiştir (Tablo 1). Analiz birimi tek bir Instagram gönderisidir. Buna görsel ve görsele ait hashtagler, emojiler ve caption/ metin kısımları dâhildir. Belirtilen tarihlerde her iki adaydan toplanan 282 gönderiye nicel içerik analizi yapılmıştır. İçerik analizi, çok çeşitli medya mesajlarının sistematik bir şekilde incelemesine olanak sağlayan ve medya mesajlarını analiz etmek için yaygın bir şekilde uygulanan bir yöntemdir (Singletary, 1994; Stacks ve Hocking, 1992). Bu sebeple içerik analizi yöntemi sosyal medya içeriği gibi internet üzerinden indirilip saklanabilen verileri analiz etmek için iyi bir seçenektir (Melek, 2015). İçerik analizini uygulayabilmek için verilerin sistematik ve objektif bir şekilde kodlanmasını sağlayacak bir kodlama cetveli gerekmektedir. Mevcut içerik analizinde Russmann ve Svensson'ın (2016) tasarladığ 1 ve Filimonov vd.,'nin (2016) uygulamasını yaptığı Instagram'a özel kodlama cetveli kullanılmıştır.

Tablo 1. Adaylar ve Instagram Örneklemi

\begin{tabular}{lll}
\hline & Donald Trump & Joe Biden \\
\hline Siyasi Parti & Cumhuriyetçi Parti & Demokratik Parti \\
Instagram Hesabı & $@$ realdonaldtrump & @joebiden \\
Takipçi $(N)$ & 24.4 milyon & 13.4 milyon \\
Fotoğraf $(N)$ & 92 & 190 \\
Zaman Aralığ 1 & 3 Ekim-3 Kasım 2020 & 3 Ekim-3 Kasım 2020 \\
\hline
\end{tabular}

Çalışmanın ve kodlama cetvelinin yapısı gereği videolar çalışmaya dâhil edilmemiştir. Yorumlar da öncül çalışmalar ışı̆̆ında siyasi aktörlerin kendilerine yapılan yorumlara cevap vermeye meyilli olmadıkları gerekçesiyle araştırma dışında tutulmuştur (ör. Filimonov vd., 2016; Russmann, 2012; Sweetser ve Lariscy, 2008). Son olarak, seçim döneminden sonra örnekleme yapıldığı ve Instagram "hikâyeleri" ise sadece 24 saat aktif kaldığg için hikâyeler de çalışma dışında tutulmuştur.

Russmann ve Svensson (2016)'ın Instagram'ın siyasi kullanımını araştırmak için önerdiği kodlama cetveli, Filimonov vd. (2016: 3)'nin çalışmasında dört ana değişken üzerinden uygulanmıştır: "(1) seçim mesajlarını yayınlamak, (2) taraftarları harekete geçirmek (mobilizasyon), (3) partinin imajını yönetmek ve (4) diğer kampanya materyallerini güçlendirmek ve tamamlamak (melez kullanım)"

İlk değişken olan yayın yapma, Instagram'ın öncelikle izleyicilere siyasi duruş, söylem ve performanslar hakkında bilgi yaymak için kullanılıp kullanılmadığıyla ilgilenmektedir. Bilgi dağıtımının birincil amaç olduğu durumlarda veriler "yayın yapma" olarak kodlanmıştır (Russmann ve Svensson, 2016). 
Mobilizasyon değişkeni, kitlelerin harekete geçirilmesi ve dinamizasyonu dâhil olmak üzere harekete geçme çağrısı yapan gönderileri ifade etmektedir (Russmann ve Svensson, 2016). Bir gönderi, seçmenleri bir şekilde etkileşime girmeye, bir mitinge katılmaya, bir adayı takip etmeye veya oy vermeye davet ettiğinde veya destekçileri sandığa gitmeye çağırdığında harekete geçirici/mobilize edici olarak kodlanmıştır (Filimonov vd., 2016).

Russmann ve Svensson (2016)'1n kodlama cetvelinde partinin imaj yönetimi değişkeni, kişiselleştirme, ünlüler ve özelleştirme alt boyutlarını içermektedir. Ancak, bu kodlama cetveli Instagram'da siyasi parti kampanyalarını incelemek için geliştirilmiştir. Kişiselleştirme, parti adayının görselde yer alıp almamasıyla ilgilidir. Mevcut çalışma ise hâlihazırda adayların kişisel hesaplarına odaklandığı için kişiselleştirme alt boyutu gereksiz kalmıştır ve kodlama cetvelinden çıkarılmıştır. Nihai kodlama cetveli böylece imaj yönetimi değişkeni kapsamında iki alt boyutu içermektedir: Ünlüler ve özelleştirme. Tanınmış bir iş insanı, üst düzey bir politikacı ve / veya kamuoyu ilgisi olan kişiler gibi ünlülerin yer aldığı görseller imaj yönetimi değişkeninin ünlüler alt boyutunda kodlanmıştır (Russmann ve Svensson, 2016). Özelleştirme ise bir adayın özel / aile ortamında mı yoksa profesyonel bir ortamda mı resmedildiğiyle ilgilenmektedir. Dolayısıyla adaylar özel bir ortamda görüntülendikleri durumda özelleştirme kapsamında kodlanmıştır.

Diğer kampanya materyallerini güçlendirmek ve tamamlamayı ifade eden değişken ise melez kullanım olarak adlandırılmaktadır. Geleneksel kitle iletişim araçları, posterler, web siteleri ve Instagram dışındaki sosyal medya platformları gibi diğer kampanya araçlarına açık bir referans olan görseller melez kullanım altında kodlanmıştır (Russmann ve Svensson, 2016).

Joe Biden'a ait 190, Donald Trump'a ait 92 olmak üzere toplam 282 gönderi yukarıda açıklanan kodlama cetveli kullanılarak var $=1$ ve yok $=0$ şeklinde bir veya birden fazla değişken altında kodlanmıştır. Kodlayıcılar arası güvenilirliği ölçmek için, iki kodlayıcı arasındaki Krippendorff's Alpha hesaplanmıştır ve genel uyum yüksek çıkmıştır ( $\alpha=$ 0.88). Ardından kodlanan veriye tanımlayıcı analiz yapılmıştır.

\section{Bulgular}

Analiz sonuçlara göre adaylar Instagram'ı en çok mobilizasyon amaciyla kullanırken, yayın yapma stratejisi her iki aday için de takip eden ikinci en yüksek kategori olmuştur. Adaylar imaj yönetimi açısından sadece profesyonel ortamlarda görüntülenmeyi ve hiçbir zaman özel/aile ortamında resmedilmemeyi tercih etmişlerdir. Bununla birlikte imaj yönetiminin ünlüler alt kategorisi her iki adayda da düşük oranda olmakla birlikte tespit edilmiştir. Melez kullanımı ise ne Biden ne de Trump tercih etmiştir.

Şekil 1'de görüleceği üzere Donald Trump gönderilerinde \%52 oranında mobilizasyon stratejisini kullanmıştır. Aynı strateji Joe Biden'da ise \%62.5 olarak görülmektedir. Her iki adayın da en yüksek oranda kullandıkları bu stratejiyi birbirleriyle kıyasladığımızda ise Biden'ın daha yüksek oranda kullandığı tespit edilmiştir. Yayın yapma stratejilerine baktığımızda Trump'ın \%40, Biden'ın ise \%24 oranında seyrettiği, dolayısyla Trump'ın Biden'a göre daha çok bu stratejiyi uyguladığı görülmektedir. 
Öncül çalışmalar, Instagram'ın hala siyasi kampanyalar için oldukça yeni bir araç olduğunu, bu nedenle, adayların kullanım kalıplarının yayın odaklı eski medya kullanım alışkanlıklarını takip ediyor olabileceğine işaret etmektedir (Filimonov vd., 2016). Ancak bu çalışmalar ileride adayların kullanım kalıplarında değişim olabileceğine de vurgu yapmıştır. Nitekim mevcut araştırmada adaylar Instagram'ın mobilize edici gücüne yönelik bir strateji geliştirmiş ve geleneksel medya kampanyalarından kalma yayın yapma odaklı kullanım daha geri plana itilmiştir. Şekil 1'de görüldüğü üzere adayların kullanım stratejileri oransal büyüklük açısından aynı sırayı takip etmektedir (1- Mobilizasyon, 2- Yayın yapma, 3- İmaj yönetimi - ünlüler), ancak Biden'1n mobilizasyon stratejisi Trump'a göre daha güçlüyken, Trump'ın ise yayın yapma stratejisi Biden'a göre daha güçlü seyretmektedir. İmaj yönetiminin ünlüler alt kategorisinde Biden'ın Trump'a göre biraz daha önde olduğu da bir başka bulgu olarak yansımaktadır.

Şekil 1. Adayların stratejik kullanım karşılaştırması

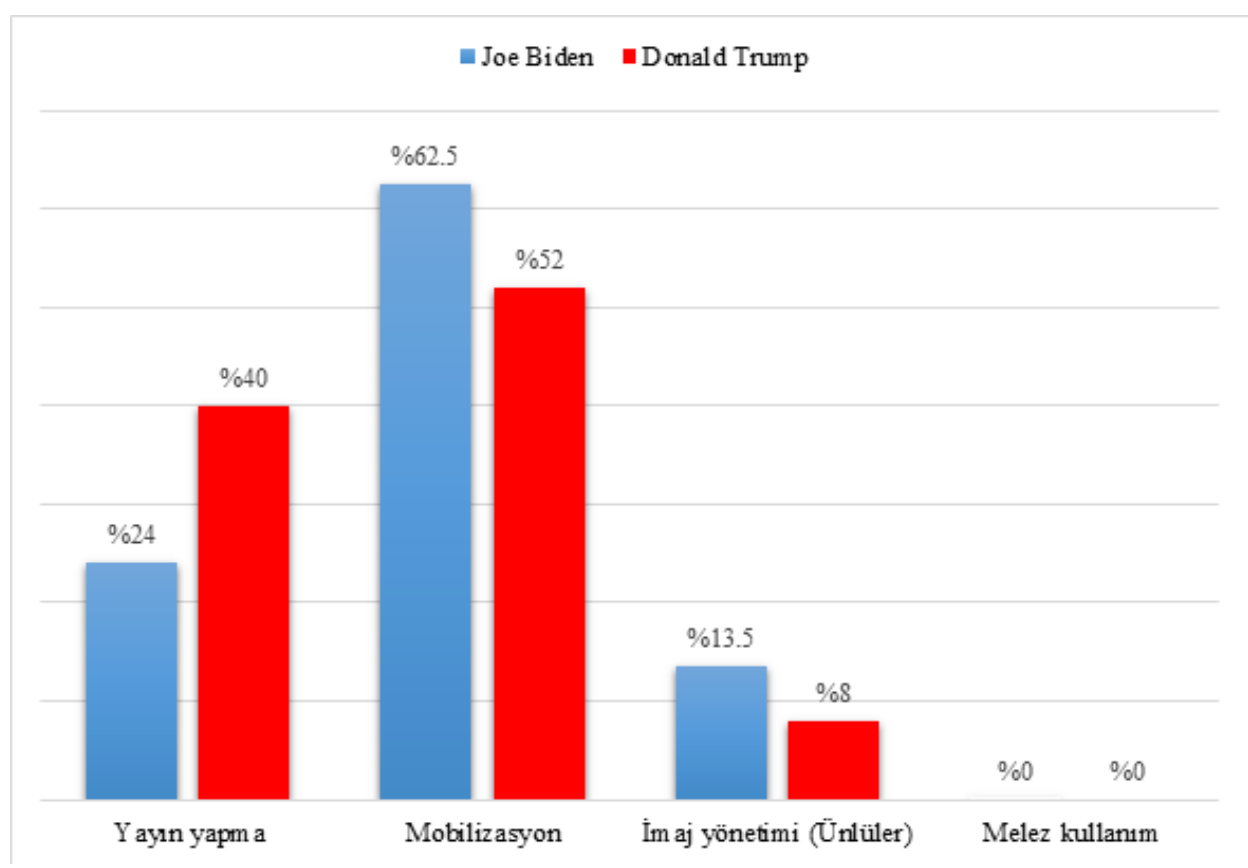

Adayların paylaşımlarında dikkat çeken niteliksel unsurlara gelirsek Biden'ın hile tablosu (cheat sheet) şeklinde rakibinin yalanlarını ortaya koyduğu görsellere sıklıkla başvurduğu görülmüştür. Bununla birlikte mobilizasyon stratejisini imaj yönetimiyle birleştirdiği, Obama ve Kamala Harris ile birlikte seçmenleri oy vermeye çağırdıkları görüntülere yer verdiği de dikkat çekmiştir (Şekil 2 ve Şekil 3). 
Şekil 2. Biden ve Obama (Mobilizasyon ve İmaj Yönetimi-Ünlüler)

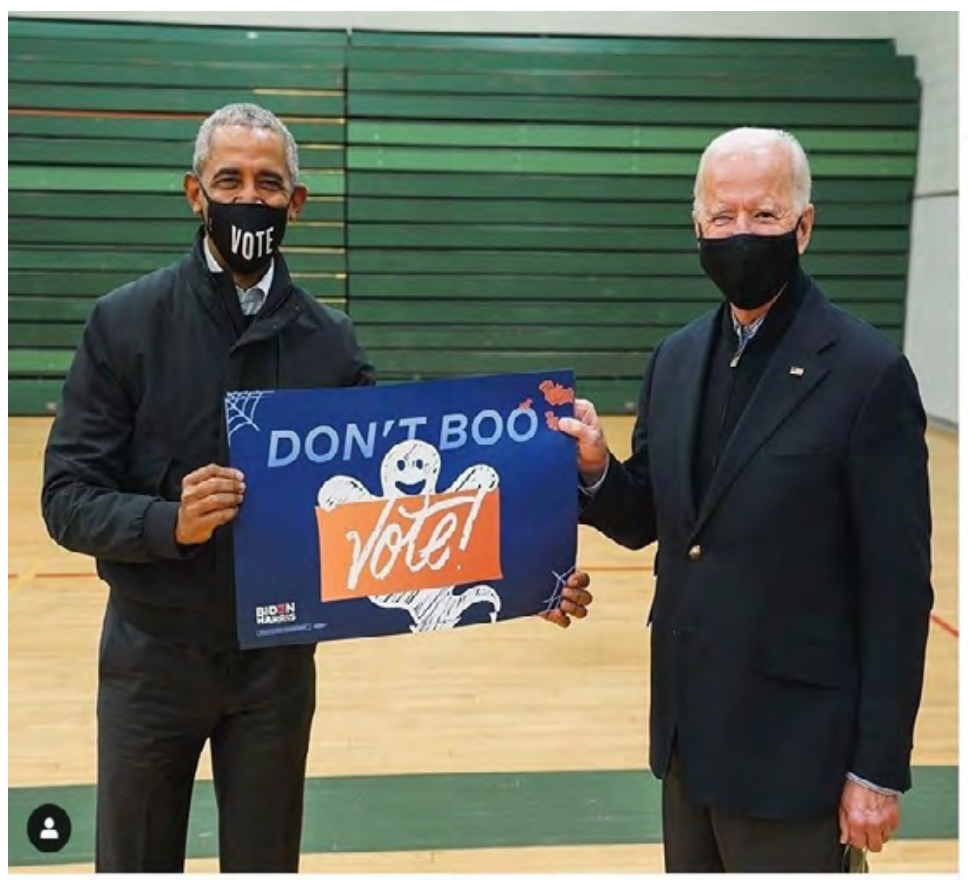

joebiden $\bullet \cdot$ Takip Et

joebiden 0 Don't ghost us this Election Day - vote!

$2 \mathrm{~h}$

$\bigcirc Q \nabla$

ve diğer kişiler beğendi

Şekil 3. Biden ve Harris (Mobilizasyon ve İmaj Yönetimi-Ünlüler)

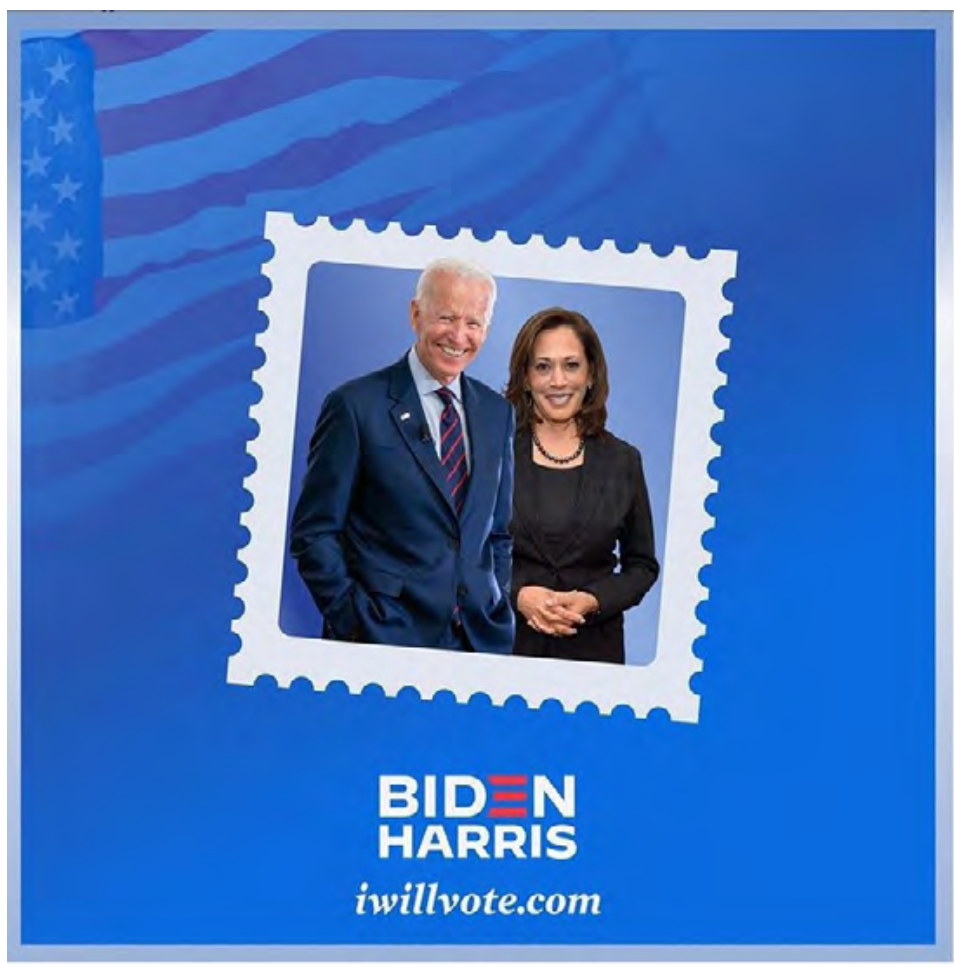

joebiden $\bullet \cdot$ Takip Et

joebiden 0 Folks are starting to vote across the country. Are you taking steps to make sure your voice is heard?

iwillvote.com. Link in my bio.

$2 \mathrm{~h}$

$\circlearrowleft \bigcirc \nabla$

ve diğer kişiler begendi
W 
Biden bununla birlikte yayın yapma stratejilerinde ise güncel siyasi sorunlara değinmiş ve 1 rkçılık, adalet, ekonomi, sağl1k sistemi gibi konulardaki duruşunu ortaya koyan paylaşımlar tercih etmiştir (Şekil 4).

Şekil 4. Biden’ın “Black Lives Matter” (Siyahların Hayatı Önemlidir) Paylaşımı (Yayın Yapma)

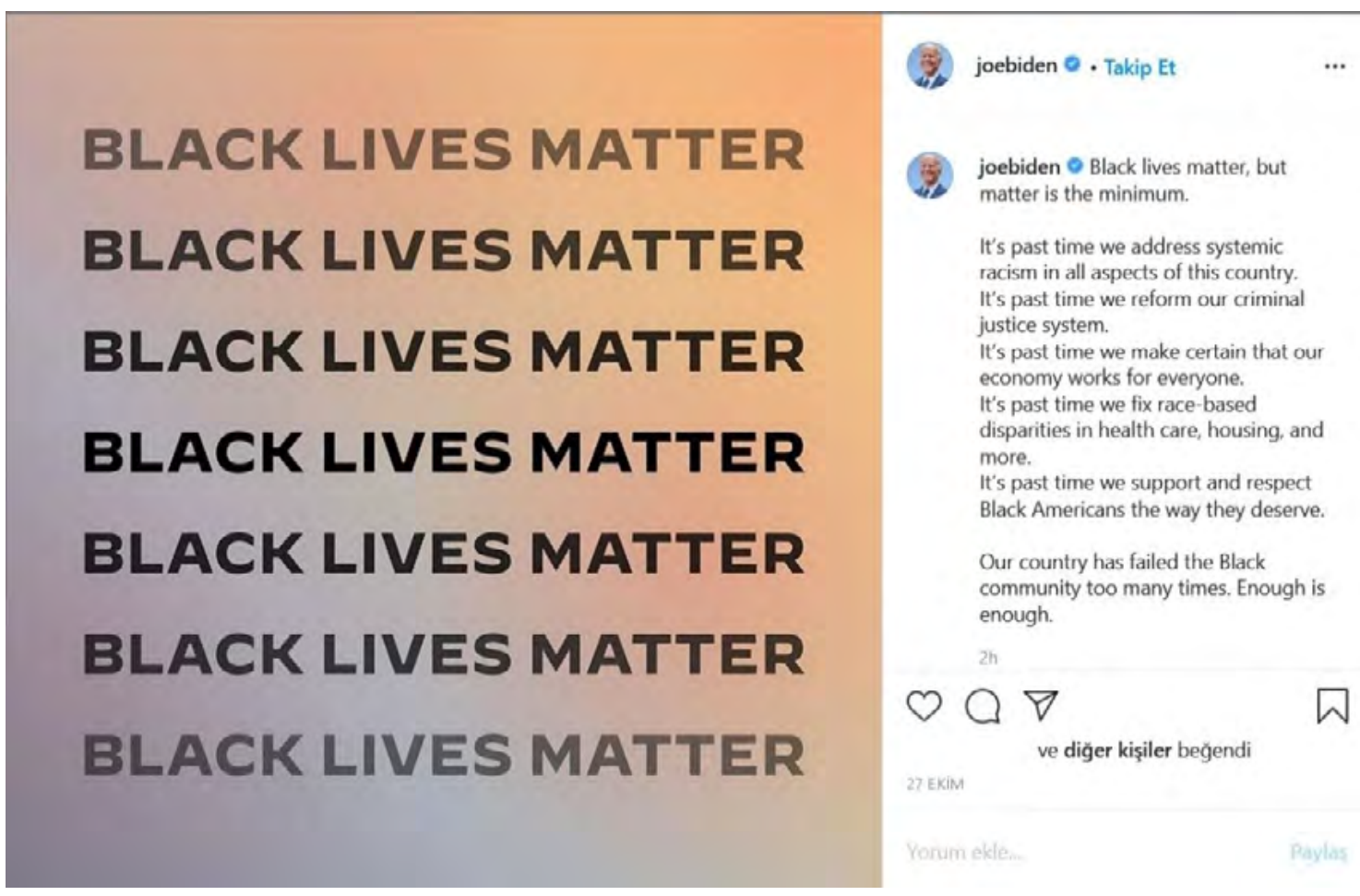

Trump'ın paylaşımlarına yakından bakıldığında genelde farklı şehirlerde mitinglerinden fotoğraflar paylaştığı görülmüştür (Şekil 5). Bu paylaşımlar da genellikle siyasi tutumuyla ilgili bilgi içeriğiyle veya "teşekkürler" ve "oy verin" mesajları eşliğinde verilmiştir.

Şekil 5. Trump Mitingi (Yayın Yapma ve Mobilizasyon)

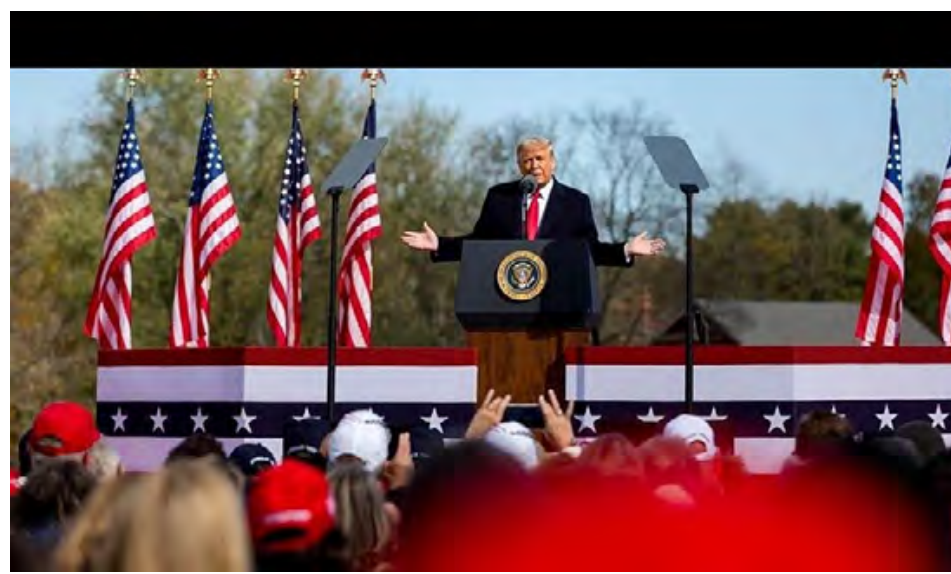

realdonaldtrump \% - Takip Et
Newtown, Bucks County, Pennsylvania
realdonaldtrump O Our ECONOMY is
now surging back faster, better, bigger
and stronger than any nation on earth.
We just had the best quarter of
ECONOMIC GROWTH EVER recorded -
a $33.1 \%$ increase, and next year will be
the GREATEST ECONOMIC YEAR in the
history of our Country!
Vote.DonaldJTrump.com
2h 
Trump'ın imaj yönetimi stratejisine giren paylaşımları ise Biden gibi ünlüler kategorisindedir. Bu kategoride yer alan ve dikkat çeken bir paylaşımında ülkenin önde gelen yüksek mahkeme yargıcı ile yan yana yürümektedir (Şekil 6).

Şekil 6. Trump ve ABD Yüksek Mahkemesi Yargıcı Amy Coney Barrett (İmaj Yönetimi-Ünlüler)

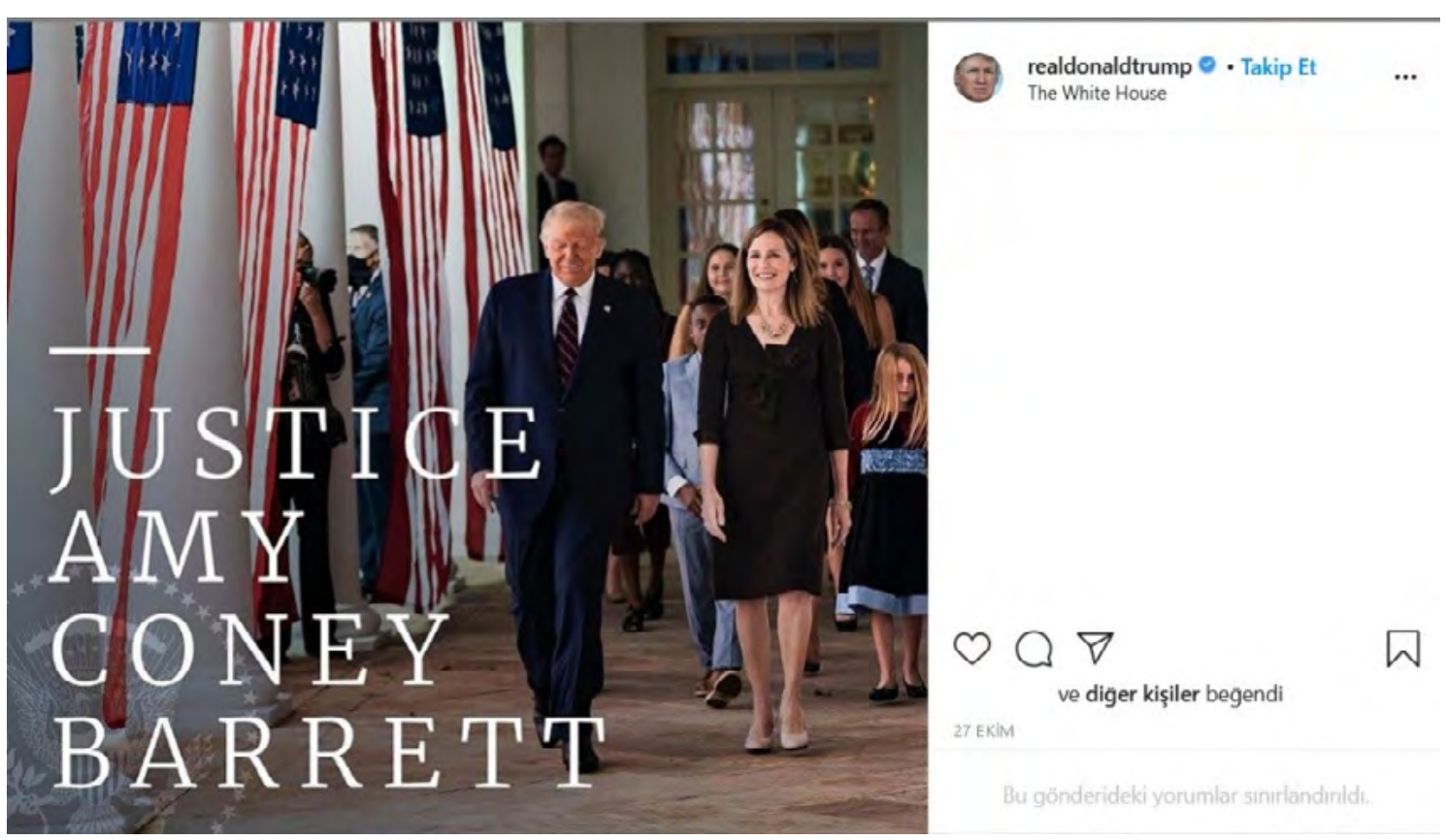

Yine mobilizasyon stratejisini önde tutan Trump'ın zaman zaman geleneksel medyada çıkan yayınları paylaşarak seçmeni \#vote ve \#maga (make America great again) hashtag'leriyle oy vermeye davet ettiği görülmüş̧ür (Şekil 7).

Şekil 7. Trump Gazete Manşeti Görüntüsü (Mobilizasyon)
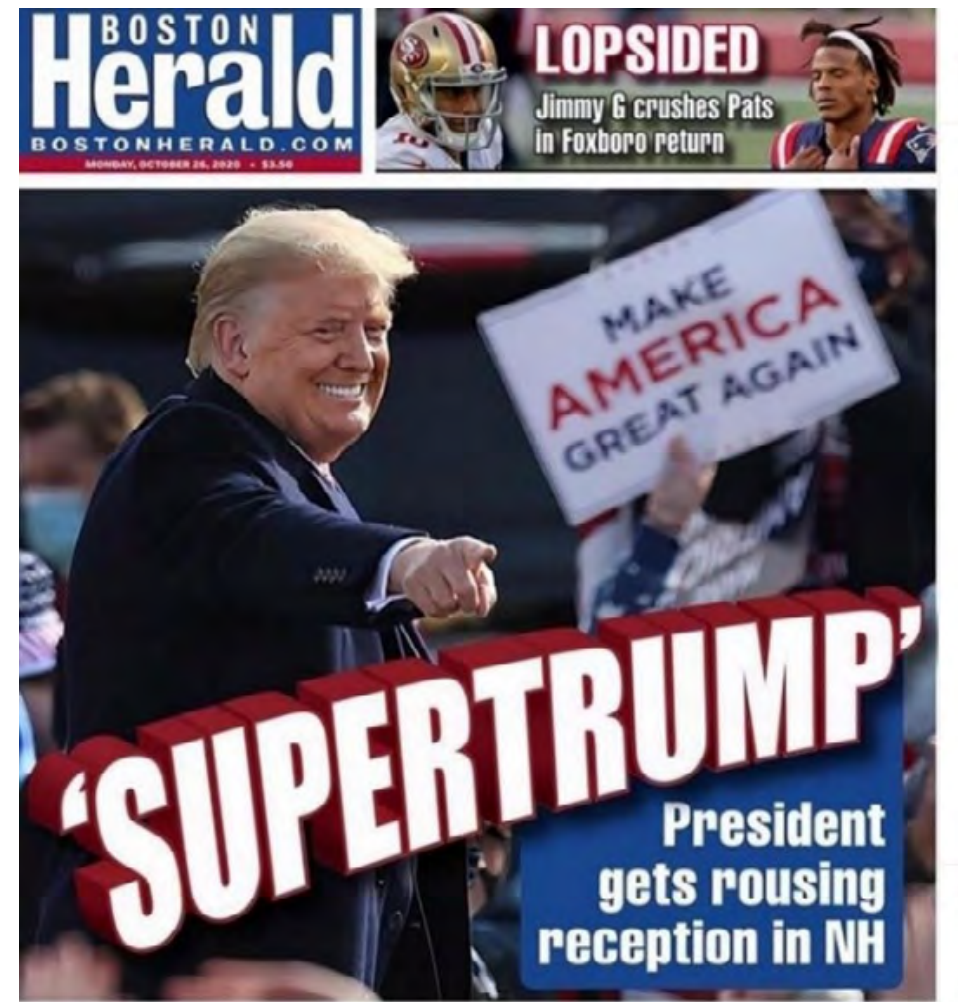

realdonaldtrump $\odot$ • Takip Et

realdonaldtrump 0 Vote.DonaldJTrump.com \#VOTE \#MAGA

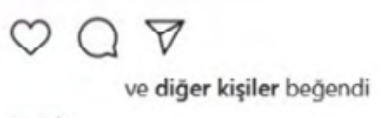


Kodlama cetvelinde imaj yönetimi ünlüler ve özelleştirme şeklinde iki alt boyut altında kodlanmıştır (Filimonov vd., 2016; Russmann ve Svensson, 2016). Dolayısıyla tanınmış bir iş insanı, üst düzey bir politikacı ve / veya kamuoyu ilgisi olan kişiler gibi ünlülerin yer aldığı görseller imaj yönetimi değişkeninin ünlüler alt boyutunda kodlanırken özelleştirme ise bir adayın özel / aile ortamında mı yoksa profesyonel bir ortamda $\mathrm{m} 1$ resmedildiğiyle ilgilenmektedir. Dolayısıyla adaylar özel bir ortamda görüntülendikleri durumda özelleştirme kapsamında kodlanmıştır. Her iki adayın da gönderileri incelendiğinde paylaşımlarının tamamında profesyonel ortamlarda görüntülendikleri tespit edilmiştir. Biden sadece birkaç fotoğrafta eşiyle görüntülenirken Trump'ın paylaşımlarında sıklıkla eşi ve çocuklarına yer verdiği dikkat çekmiştir. Tüm bu fotoğraflar profesyonel ortamlarda görüntülendiği için imaj yönetimi kapsamında değildir. Her iki aday da imaj yönetimini ünlü politikacılar veya üst düzey bürokratlarla görüntülenerek gerçekleştirmiştir.

Her iki adayın da seçmeni mobilize etmek için daha çok hashtag ve yazılı mesajlar yoluyla oy vermeye çağırdığı göze çarpmaktadır. Mobilizasyon değişkeni, kitlelerin harekete geçirilmesi ve dinamizasyonu dâhil olmak üzere harekete geçme çağrısı yapan, seçmenleri bir şekilde etkileşime girmeye, oy kullanmaya, bir mitinge katılmaya, bir adayı takip etmeye yönlendiren durumları ifade etmektedir (Filimonov vd., 2016; Russmann ve Svensson, 2016). Ancak her iki adayın da bu stratejiyi daha dar bir kapsamda ve çoğu kez sadece seçmeni sandığa yönlendirme maksatlı kullandığı tespit edilmiştir.

\section{Sonuç ve Öneriler}

Geçmiş araştırmalar, görsellerin siyasal iletişimdeki önemini ortaya koymuştur. Stratejik olarak kullanılan görsel imgeler, politikacılara belirli, amaçlanan anlamları aktarmaları ve imajlarını şekillendirmeleri için firsatlar sağlamaktadır. Siyasi liderlerin imaj yönetimi için Instagram kullanımlarındaki artışa rağmen, politikacıların kendilerini sunma biçimleri ve stratejilerini araştıran çalışmalar hâlâ azdır (Filimonov v.d., 2016; Lalancette ve Raynauld, 2019; Melek ve Müyesseroğlu, 2021; Muñoz ve Towner, 2017; Steffan, 2020; Uluçay ve Melek, basım aşamasında). Bu nedenle mevcut çalışma, Instagram'da gerçekleştirilen görsel seçim kampanyalarında kullanılan stratejiler hakkındaki akademik yazına katkıda bulunmayı amaçlamıştır. Amerika'da yapılan 2020 başkanlık seçimi adayları Donald Trump ve Joe Biden'ın kişisel Instagram hesapları incelenerek, adayların Instagram'1 hangi siyasi stratejilerle kullandıkları tespit edilmiştir.

Filimonov v.d. (2016) tarafından yapılan öncül bir çalışma Instagram'ın çok sınırlı kullanıma sahip yeni bir kampanya aracı olduğunu ve bu nedenle İsveç’teki siyasi partilerin Instagram'1 mobilizasyondan ziyade yayın yapma amaçlı kullandıklarını ve melez kullanımın da gönderilerin yarısında görüldüğünü vurgulamıştır. ABD 2020 seçimlerine odaklanılan mevcut çalışma ise aksine adayların daha çok seçmeni mobilize etmeye yöneldiklerini, yayın yapma stratejisinin ise ikinci planda kaldığını ve melez kullanımı da asla benimsemediklerini ortaya koymuştur. Çalışma sonuçları, Williams ve Gulati'nin (2013) sosyal medyanın seçmenleri harekete geçirmek için yararlı bir araç olabileceğine yönelik bulgularını desteklemektedir. Siyasiler hızla Instagram'daki görsel kampanyalara 
dönük bilgi birikimlerini geliştirmekte ve yeni stratejiler benimsemektedirler. Bu nedenle gelecek çalışmalarda farklı ülke bağlamları ve farklı tip seçim süreçleri de (yerel, genel, başkanlık seçimi vb.) araştırılmalıdır.

Mevcut çalışma fotoğraflarla ve her ne kadar yoğun olsa da seçim kampanyasının son ayıyla kısıtlıdır. Gelecek çalışmalarda video ve hikâye özellikleri de araştırılıp Instagram'ın kullanımıyla ilgili daha geniş çaplı tespit yapmak yararlı olacaktır. Yine seçim kampanyası döneminde zamana yayılan bir inceleme yapılarak süreç boyunca adayların stratejilerindeki olası dönemsel değişimler tespit edilebilir. Farklı görsel sosyal medya siteleri arasında yapılabilecek karşılaştırmalı çalışmalar da bilgi verici nitelikte olacaktır. Bununla birlikte farklı ülkeler arası karşılaştırmalı çalışmalar yapmak da daha kapsayıcı olma potansiyeli taşımaktadır.

Son olarak gelecek çalışmalarda sosyal medya ve Instagram özelinde yapılan görsel kampanyaların seçmen davranışı ve siyasi katılıma olan etkileri de araştııılmalıdır.

\section{Kaynaklar}

And1, S., Aytaç, S. E., ve Çarkoğlu, A. (2020). "Internet and social media use and political knowledge: Evidence from Turkey", Mediterranean Politics, 25(5), s. 579-599. doi:10.1080/13629395.2019.1635816

Blair, J. Anthony, (2012). The Rhetoric of Visual Arguments. C. Tindale içinde, Groundwork in the Theory of Argumentation (s. 261-279). London: Springer.

Bode, L., ve Dalrymple, K. E. (2016). "Politics in 140 Characters or Less: Campaign Communication, Network Interaction, and Political Participation in Twitter", Journal of Political Marketing, 15(4), s. 311-332. doi:10.1080/15377857.2014.959686

Bode, L., ve Vraga, E. K. (2018). "Studying Politics Across Media", Political Communication, 35(1), s. 1-7. doi:10.1080/10584609.2017.1334730

Borah, Porismita, (2016). "Political Facebook use: Campaign strategies used in 2008 and 2012 presidential elections", Journal of Information Technology \& Politics, 13(4), s. 326-338. doi: 10.1080/19331681.2016.1163519

Bossetta, Michael, (2018). "The digital architectures of social media: Comparing political campaigning on Facebook, Twitter, Instagram, and Snapchat in the 2016 US election", Journalism and Mass Communication Quarterly, 95(2), s. 471-496.

Bucher, H.-J. ve Schumacher, P. (2006). "The relevance of attention for selecting news content. An eye-tracking study on attention patterns in the reception of print and online media", Communications, 31(3), s. 347-368.

Cmeciu, C. (2014). Beyond the online faces of Romanian candidates for the 2014 European Parliament elections: a visual framing analysis of Facebook photographic images. G. Horvath, R. K. Bako, ve E. Biro-Kaszas (Eds.), Ten Years of Facebook: Proceedings from the Third International Conference on Argumentation and Rhetoric içinde (s. 405-434). Nagyvarard, Romania: Partium Press. 
Eldin, Amira Karam, (2016). "Instagram role in influencing youth opinion in 2015 election campaign in Bahrain”, European Scientific Journal, 12(2), s. 245-257.

Enli, Gunn, (2017). "Twitter as arena for the authentic outsider: Exploring the social media campaigns of Trump and Clinton in the 2016 US presidential election", European Journal of Communication, 32(1), s. 50-61. doi:10.1177/0267323116682802

Enli, G. S., ve Skogerbø, E. (2013). "Personalized campaigns in party-centered politics: Twitter and Facebook as arenas for political communication", Information, Communication \& Society, 16(5), s. 757-774. doi: 10.1080/1369118X.2013.782330

Filimonov, K., Russmann, U., ve Svensson, J. (2016). "Picturing the party: Instagram and party campaigning in the 2014 Swedish Elections", Social Media + Society, 2(3), s. $1-11$.

Gerodimos, R., ve Justinussen, J. (2015). “Obama's 2012 Facebook campaign: Political communication in the age of the like button", Journal of Information Technology \& Politics, 12(2), s. 113-132. doi: 10.1080/19331681.2014.982266

Goldbeck, J., Grimes, J. M., ve Rogers, A. (2010). “Twitter use by the US Congress", Journal of the American Society for Information Science and Technology, 61, s. 16121621. doi: 10.1002/asi.21344

Goodnow, Trischa, (2013). "Facing off: A comparative analysis of Obama and Romney Facebook timeline photographs", American Behavioral Scientist, 57(11), s. 1584-1595.

Grabe, M. E. ve Bucy, E. P. (2009). Image Bite Politics: News and the Visual Framing of Elections, New York: Oxford University Press.

Graber, Doris A., (1996). "Say it with pictures", The Annals of the American Academy of Political and Social Science, 546(1), s. 85-96.

Graham, T., Broersma, M., Hazelhoff, K., ve van’t Haar, G. (2013). "Between broadcasting political messages and interacting with voters: The use of Twitter during the 2010 UK general election campaign", Information, Communication and Society, 16(5), s. 692-716. doi:10.1080/1369118X.2013.785581

Highfield, T., ve Leaver, T. (2015). "A Methodology for Mapping Instagram Hashtags", First Monday, 20(1). doi:10.5210/fm.v20i1.5563

Lalancette, M. ve Raynauld , V. (2019). "The power of political image: Justin Trudeau, Instagram, and celebrity politics”, American Behavioral Scientist, 63(7), s. 888924.

Liebhart, K. ve Bernhardt, P. (2017). "Political Storytelling on Instagram: Key Aspects of Alexander Van der Bellen's Successful 2016 Presidential Election Campaign”, Media and Communication, 5(4), s. 15-25.

Melek, Gizem, (2015). Medya Arası Gündem Belirleme Kuramı Çerçevesinde Hürriyet ve Twitter Üzerine Bir Çalışma. (Yayımlanmamış doktora tezi). Ege Üniversitesi, İzmir. 
Melek, Gizem, (2017). "A Study on Hürriyet and Twitter within the Framework of Intermedia Agenda-Setting”, İletişim Kuram ve Araştırma Dergisi, 44, s.17-41.

Melek, G. ve Müyesseroğlu, E. (2021). "Political Storytelling of Ekrem İmamoğlu on Instagram during 2019 Istanbul Mayoral Elections in Turkey", Visual Studies. doi: 10.1080/1472586X.2021.1975501

Metz, M., Kruikemeier, S. ve Lecheler, S. (2020). "Personalization of politics on Facebook: examining the content and effects of professional, emotional and private selfpersonalization", Information, Communication \& Society, 23(10), s. 1481-1498. doi:10. 1080/1369118X.2019.1581244

Muñoz, C. L., ve Towner, T. L. (2017). "The image is the message: Instagram marketing and the 2016 presidential primary season", Journal of Political Marketing, 16(3-4), s. 290-318. doi:10.1080/15377857.2017.1334254

Pineda, A., Bellido-Pérez, E. ve Barragán-Romero, A. (2020). “'Backstage moments during the campaign': The interactive use of Instagram by Spanish political leaders", New Media \& Society, doi:https://doi.org/10.1177/1461444820972390

Rosenberg, S. W., Bohan, L., McCaffert, P. ve Harris, K. (1986). "The image and the vote: The effect of candidate presentation on voter preference", American Journal of Political Science, 30(1), s. 108-127.

Russmann, Uta, (2012). “Online political discourse on Facebook: An analysis of political campaign communication in Austria", Journal for Political Consulting and Policy Advice, 3, s. 115-125.

Russmann, U., ve Svensson, J. (2016). How to study Instagram? Reflections on coding visual communication online. Conference for E-Democracy and Open Government. Krems, Austria.

Schill, Dan, (2012). "The visual image and the political image: A review of visual communication research in the field of political communication", Review of Communication, 12(2), s. 118-142.

Singletary, Michael W., (1994). Mass Communication Research: Contemporary Methods and Applications. White Plains, NY: Longman.

Stacks, D. W. ve Hocking, J. E. (1992). Essentials of Communication Research. New York: HarperCollins.

Statista (2021), https://www.statista.com/statistics/421169/most-followersinstagram/. Erişim Tarihi: 12.09.2021.

Steffan, Dennis, (2020). "Visual Self-Presentation Strategies of Political Candidates on Social Media Platforms: A Comparative Study", International Journal of Communication, 14, s. 3096-3118. 
Svensson, J. ve Larsson, A. O. (2016). "Interacting with Whom?: Swedish Parliamentarians on Twitter during the 2014 Elections", International Journal of E-Politics, 7(1), s. 1-15. doi:10.4018/IJEP.2016010101

Sweetser, K. D. ve Lariscy, R. W. (2008). "Candidates Make Good Friends: An Analysis of Candidates' Uses of Facebook", International Journal of Strategic Communication, 2(3), s. 175-198. doi:10.1080/15531180802178687

Towner, Terri L., (2013). “All political participation is socially networked? New media and the 2012 election”, Social Science Computer Review, 31(5), s. 527-541.

Turnbull-Dugarte, Stuart J., (2019). "Selfies, policies, or votes? Political party use of Instagram in the 2015 and 2016 Spanish general elections", Social Media + Society, 5(2), s. 1-15.

Uluçay, D. M., ve Melek, G. (basım aşamasında). "Self-Presentation Strategies and the Visual Framing of Political Leaders on Instagram: Evidence from the Eventful 2019 Istanbul Mayoral Elections", Visual Communication.

Veneti, A., Jackson, D. ve Lilleker, D. G. (2019). Visual political communication, Basingstoke: Palgrave Macmillan.

Williams, C. B. ve Gulati, G. J. (2013). "Social networks in political campaigns: Facebook and the congressional elections of 2006 and 2008", New Media \& Society, 15(1), s. 52-71. doi:https://doi.org/10.1177/1461444812457332

Destekleyen Kurum/Kuruluşlar: Herhangi bir kurum/kuruluştan destek alınmamıştır.

Çıkar Çatışması: Herhangi bir çıkar çatışması bulunmamaktadır 